\title{
Thermal Modeling of a Multilayer Integrated LC Filter for Temperature Distribution Calculation
}

\author{
Somo Coulibaly' ${ }^{1}$ Diby Kadjo Ambroise ${ }^{2}$, Loum Georges ${ }^{1}$ \\ ${ }^{1}$ Institut National Polytechnique, UMRI EEA (LARIT-SISE), Yamoussoukro, Ivory Coast \\ ${ }^{2}$ Université Félix Houphouët-Boigny, SSMT (LPMCT), Abidjan, Ivory Coast \\ Email: somo_c@yahoo.fr
}

How to cite this paper: Coulibaly, S., Ambroise, D.K. and Georges, L. (2019) Thermal Modeling of a Multilayer Integrated LC Filter for Temperature Distribution Calculation. Engineering, 11, 759-767.

https://doi.org/10.4236/eng.2019.1111050

Received: October 1, 2019

Accepted: November 12, 2019

Published: November 15, 2019

Copyright (c) 2019 by author(s) and Scientific Research Publishing Inc. This work is licensed under the Creative Commons Attribution International License (CC BY 4.0).

http://creativecommons.org/licenses/by/4.0/

\begin{abstract}
Thermal behavior of integrated passive components has become an important issue when designing these components. This paper presents the thermal modeling of a multilayer integrated LC filter used in DC-DC step-down converter for temperature distribution calculation. The approach used for this analysis is based on thermal equivalent circuit. Temperature distribution is obtained from algebraic equation, which is in vector and matrix form. The results of analytical calculation are compared with simulation results from finite element method. These results showed a good correlation.
\end{abstract}

\section{Keywords}

Thermal Modeling, Integrated LC Filter, Temperature Distribution, F. E. M. Simulation

\section{Introduction}

Thermal design of electronic components and systems is to ensure that the temperature rise caused by the losses remains within acceptable limits. In power electronic converter, temperature causes around $54 \%$ of all the converter failure [1]. It is therefore necessary to investigate the structures of the integrated LC passive module thermally to guarantee reliable operation of the integrated power module. Thermal modeling and simulation have become essential parts in process design. These integrated components are essentially magnetic components. Modeling these components provide good study of investigation of the temperature evolution through the integrated component.

However, modeling magnetic components requires knowledge of electromagnetic losses. These losses are due to current flow in the windings ("copper losses"), to the temporal variation of the magnetic field in the magnetic cores ("iron 
losses") and to link ("connection loss"). Due to the complexity of determining these losses, many approaches are used to investigate the temperature evolution inside the integrated component.

In this paper, we propose compact thermal model that can be integrated into mathematical tools to achieve temperature distribution across the integrated LC component. Calculation of temperature distribution is based on the assumption that the temperature line is linear under steady state.

In order to verify the results of the thermal resistance network approach, it is compared to thermal Finite Element Method simulation.

\section{Integrated LC Filter Overview}

The studied integrated LC filter is shown in Figure 1 [2] [3]. It consists of a PCB planar inductor sandwiched between two ferrite layers, and a capacitive part made of ferrite multilayer capacitors. The ferrite layers are flexible ferrite sheets used for both inductor magnetic core and capacitor dielectric medium. Inductor and capacitor parts are stacked together in series connection to give the integrated LC component.

\section{Thermal Modeling of the Integrated LC Filter}

The thermal analysis of an integrated component consists of studying its ability to evacuate heat to the outside. The purpose of such a study is to predict the risks of overheating of the different materials.

If one side of a solid is warmer than the other side, then heat flow goes through the body from the warmer side to the cooler one. Heat flow mechanism through a solid material is illustrated by Figure 2. Difference temperature from inside the component to outside consists of heat conduction and heat convection.

The rate of heat loss is given by [4]:

$$
Q=\frac{\lambda \cdot A \cdot\left(T_{1}-T_{2}\right)}{d}=\frac{T_{1}-T_{2}}{R_{t h}}
$$

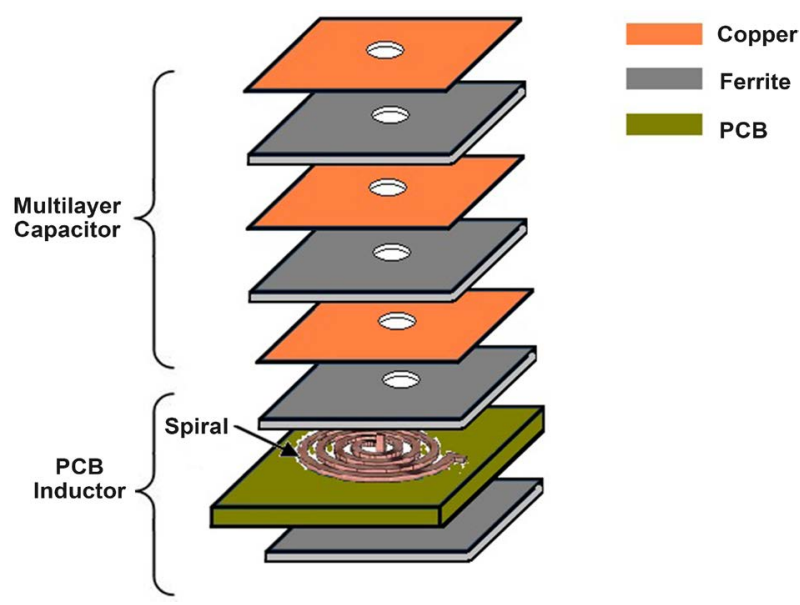

Figure 1. Exploded view of the structure [3]. 


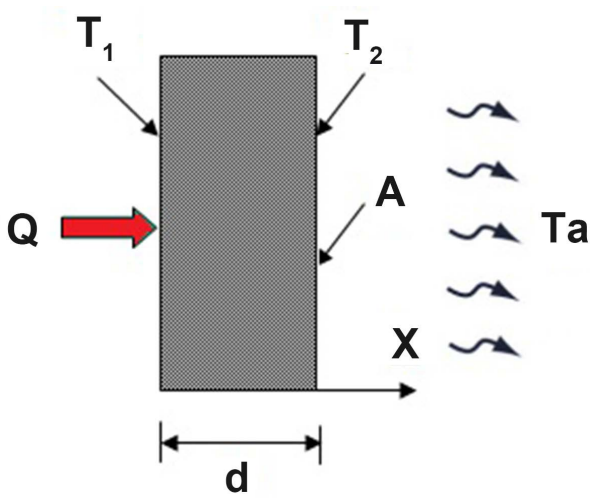

Figure 2. Heat Flow illustration in a solid material.

where:

$R_{t h}=\frac{d}{\lambda \cdot A}$ is the thermal resistance of the solid [K/W];

$Q=$ the heat flow $[\mathrm{W}]$;

$T_{1}$ and $T_{L}=$ the temperatures at the ends of the solid material [K];

$d=$ the thickness crossed by the heat source $[\mathrm{m}]$;

$A=$ the surface of the heat source $\left[\mathrm{m}^{2}\right]$;

$\lambda=$ the thermal conductivity of the material $[\mathrm{W} /(\mathrm{m} \cdot \mathrm{K})]$.

On the outside surface of the solid material, heat transfer is mainly heat convection which is conducted between air and the surface. It can be obtained based on the Newton's law of cooling [4]:

$$
Q=h \cdot A \cdot\left(T_{f}-T_{a}\right)=\frac{T_{f}-T_{a}}{R_{t h}}
$$

where:

$Q=$ rate of heat flow $(\mathrm{W})$;

$R_{t h}=\frac{1}{h \cdot A}$ is the thermal resistance for convection $(\mathrm{K} / \mathrm{W})$;

$h=$ convective heat transfer coefficient $\left(\mathrm{W} / \mathrm{m}^{2} \mathrm{~K}\right)$;

$A=$ cross sectional area $\left(\mathrm{m}^{2}\right)$;

$T_{f}=$ surface temperature $(\mathrm{K})$;

$T_{a}=$ ambient temperature $(\mathrm{K})$.

The thermal system of Figure 2 can be converted into an equivalent electrical system as shown in Figure 3 where voltage plays the same role as temperature (Equation (1)).

$R_{t h 1}$ is the thermal resistance of the solid for conduction; $R_{t h 2}$ is the thermal resistance for convection.

Since $Q$ is constant throughout the network, it follows that:

$$
Q=\frac{T_{1}-T_{2}}{R_{t h 1}}=\frac{T_{2}-T_{a}}{R_{t h 2}}
$$

Knowing the heat flow $Q$, the ambient temperature Ta and the solid material properties, the unknown temperatures $T_{1}$ and $T_{2}$ can be calculated. 


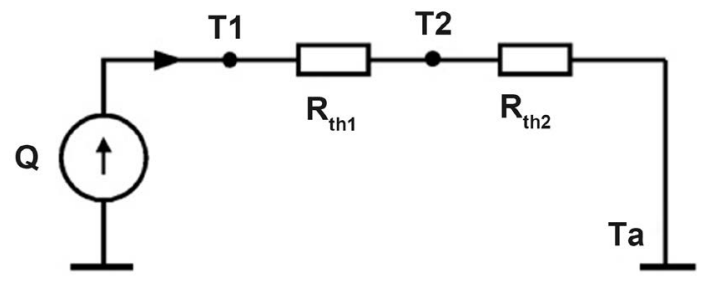

Figure 3. Equivalent thermal model.

This concept of thermal resistance circuit can be easily applied to the multilayer integrated LC component.

The heat source generated inside le component by the spiral winding copper is drained towards ambient air taking two dissipation paths as shown in Figure 4. In this representation, we considered that capacitor part of the integrated LC filter is made of two layers of ferrite material for demonstration purpose. In practice, number of ferrite layers depends on the value of capacitor.

Knowing the loss in the spiral winding, the thermal model must allow determining the operating temperature in some points of the component along the heat flowing path.

Thermal modeling of an integrated multilayer structure is quite complex. To simplify the modeling of this component, we make a number of assumptions [5]:

- Each layer must satisfy the heat conduction equation.

- Steady state conduction;

- One-dimensional heat flow;

- Constant properties of materials;

- Uniform heat flow in each layer;

- Perfect contact between layers;

- Perfectly flat layers with uniform thickness;

- Component boundaries (top and bottom faces) convect heat to the ambient on both sides.

From the cross section view of the structure shown in Figure 4, the equivalent thermal model of the structure can be represented as interconnection of the thermal resistance of each layer as in electrical circuit (Figure 5).

In this representation, $R_{\text {thcu }}, R_{\text {thfe }}$ and $R_{\text {thFR }}$ stand for the thermal resistances of copper, ferrite and PCB layers, respectively.

The conduction path 1 consists of seven resistors: $R_{\text {thcu }} / 2$ (resistance between the center of the conductor and its lower surface), $R_{\text {thfe }}$ (resistance due to the ferrite layer) and $R_{\text {thcu }}$ (resistance due to the copper layer).

The conduction path 2 consists of two resistors: $R_{\text {thcu }} / 2$ (resistance between the center of the conductor and its upper surface), $R_{t h F R 4}$ (resistance due to the epoxy $\mathrm{PCB}$ ) and $R_{\text {thfe }}$ (resistance due to the ferrite layer).

The temperature at the center of the conductive spiral is noted $T_{\max }$ and $T_{c u}$ is the temperature at each face of the spiral windings. The temperatures $T_{f 1}$ and $T_{f 2}$ are the temperatures on the outer flat faces in contact with the ambient air. Heat transfer exchange is convection on these faces. 


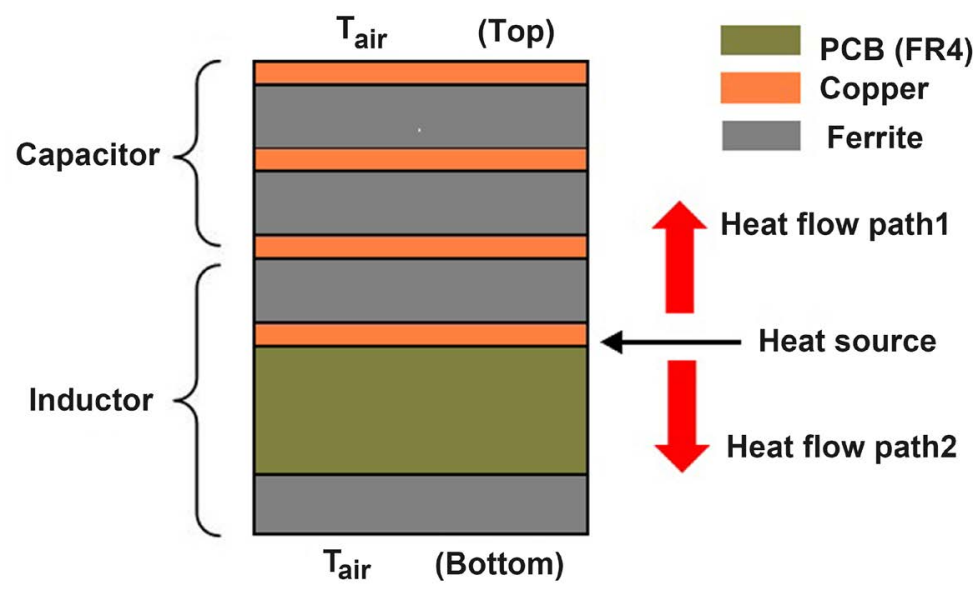

Figure 4. Cross section of the integrated LC component showing heat flow paths from heat source to the outside.

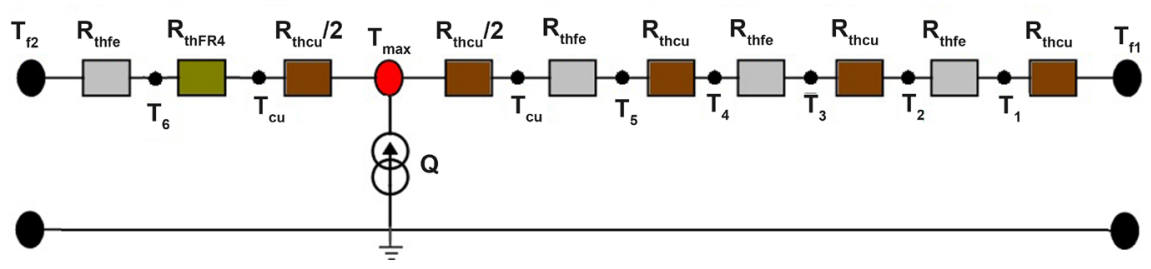

Figure 5. Integrated LC component thermal model.

Because of the high thermal conductivity of the copper and its small thickness $(35 \mu \mathrm{m})$, the temperature may be considered as uniform inside the spiral winding, and then $T_{c u}$ and $T_{\max }$ are equal. We can therefore neglect the thermal resistance $R_{\text {thcu }} / 2$ on each side of $T_{\max }$. This leads to the reduced model circuit shown in Figure 6.

The heat source $Q$ generated by the copper spiral winding at the node $T_{\max }$ is spread into two heat sources $Q_{1}$ and $Q_{2}$ such that $Q=Q_{1}+Q_{2}$ because of energy conservation.

Finally, the problem is to determine temperatures $T_{\max }, T_{1}, T_{2}, T_{3}, T_{f}$ and $T_{f 2}$ from the knowing thermal resistors $R_{\text {thfe }}, R_{\text {thFR4 }}, R_{\text {thcu }}$ and the generated heat $Q$. Temperature $T_{\text {air }}$ is fixed by forced or natural convection on both flat faces of the integrated LC component.

Under the above assumptions, temperature distribution can be calculated from the following equations:

$$
\begin{gathered}
Q_{1}=K_{f e} \cdot\left(T_{\max }-T_{2}\right)=K_{f e} \cdot\left(T_{2}-T_{1}\right) \\
Q_{1}=K_{f e} \cdot\left(T_{2}-T_{1}\right)=K_{f e} \cdot\left(T_{1}-T_{f 1}\right) \\
Q_{1}=K_{f e} \cdot\left(T_{1}-T_{f 1}\right)=h \cdot A \cdot\left(T_{f 1}-T_{\text {air }}\right) \\
Q_{2}=K_{F R 4} \cdot\left(T_{\max }-T_{3}\right)=K_{f e} \cdot\left(T_{3}-T_{f 2}\right) \\
Q_{2}=K_{f e} \cdot\left(T_{3}-T_{f 2}\right)=h \cdot A \cdot\left(T_{f 2}-T_{\text {air }}\right) \\
Q=K_{F R 4} \cdot\left(T_{\max }-T_{3}\right)+K_{f e} \cdot\left(T_{\max }-T_{2}\right)
\end{gathered}
$$




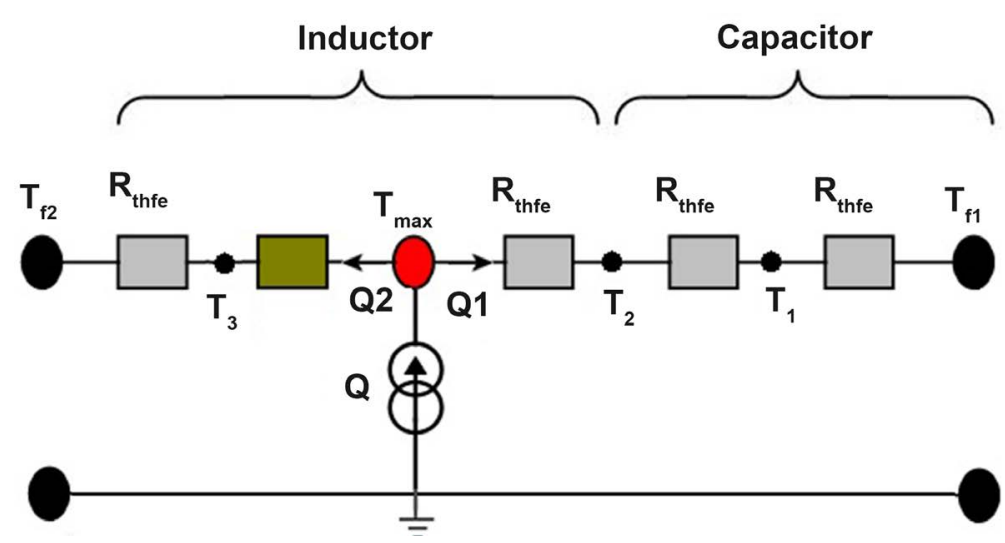

Figure 6. Reduced thermal model of integrated LC component.

where $h\left[\mathrm{~W} /\left(\mathrm{m}^{2} \cdot \mathrm{K}\right)\right]$ is the coefficient of heat transfer by convection, $\mathrm{A}\left[\mathrm{m}^{2}\right]$ the area of the layers of materials, $K_{F R 4}$ and $K_{f e}$ are defined as the thermal conductance (inverse of thermal resistance) of PCB and ferrite layers, respectively.

These simultaneous equations can be rearranged by putting unknown parameters $\left(T_{f}, T_{3}, T_{\max }, T_{2}, T_{1}, T_{f}\right)$ on one side and the known ones on the other side. This leads to the matrix equation $\left[K_{t h}\right] \times[T]=[F]$ represented by Equation (10) where $K_{t h}$ is matrix of thermal Conductance, T the unknown temperature vector and $\mathrm{F}$ the heat source vector.

$$
\left[\begin{array}{cccccc}
0 & 0 & K_{f e} & -2 \cdot K_{f e} & K_{f e} & 0 \\
0 & 0 & 0 & K_{f e} & -2 \cdot K_{f e} & K_{f e} \\
0 & 0 & 0 & 0 & K_{f e} & K_{f e} \\
K_{f e} & K_{f e} & K_{F R 4} & 0 & 0 & 0 \\
-\left(K_{f e}+h \cdot A\right) & K_{f e} & 0 & 0 & 0 & 0 \\
0 & -K_{F R 4} & K_{F R 4}+K_{f e} & -K_{f e} & 0 & 0
\end{array}\right] \times\left[\begin{array}{c}
T_{f 2} \\
T_{3} \\
T_{\max } \\
T_{2} \\
T \\
T_{f 1}
\end{array}\right]=\left[\begin{array}{c}
0 \\
0 \\
-h \cdot A \cdot T_{a i r} \\
0 \\
-h \cdot A \cdot T_{a i r} \\
0
\end{array}\right]
$$

The unknown nodal temperatures are given by the following relation:

$$
[T]=\left[K_{t h}\right]^{-1} \cdot[F]
$$

The solution can be obtained by using numerical calculation software such as MATLAB.

\section{Results and Discussions}

To verify the solution of the analytical method, "Heat Flow Problem" module of FEMM software [6] [7] has been used. The values of the properties of the materials used in the design of the integrated LC filter are given in Table 1.

Calculated thermal resistance and their corresponding thermal conductance are given in Table 2.

These calculations were made by considering the spiral winding copper as a uniform disk with $60 \mathrm{~mm}$ for diameter. That gives an exchange area $\mathrm{A}=2.83 \times$ $10^{-3} \mathrm{~m}^{2}$. 
Table 1 . Thermal conductivity $\lambda$ of different materials.

\begin{tabular}{ccc}
\hline Material & $\lambda[\mathrm{W} / \mathrm{mK})]$ & Thickness $(\mathrm{mm})$ \\
\hline PCB_FR4 & 0.3 & 1.6 \\
Copper & 401 & 0.035 \\
Ferrite & 1.5 & 0.2 \\
\hline
\end{tabular}

Table 2. Values of thermal resistance and corresponding thermal conductance.

\begin{tabular}{ccc}
\hline Material & Thermal resistance $\left({ }^{\circ} \mathrm{C} / \mathrm{W}\right)$ & Thermal conductance $\left(\mathrm{W} /{ }^{\circ} \mathrm{C}\right)$ \\
\hline PCB_FR4 & $R_{\text {thcu }}=3.08 \times 10^{-5}$ & 32,394 \\
Copper & $R_{\text {thFR }}=0.707$ & 21.206 \\
Ferrite & $R_{\text {thfe }}=0.047$ & 1.413 \\
\hline
\end{tabular}

Since for the design of the integrated LC filter, inductor and capacitor values needed depend on material thicknesses and properties, the calculation of the temperature at each of the six nodesinvolve three parameters which are:

- Ambient temperature near top and bottom faces;

- Convective heat-transfer coefficient on faces $f_{1}$ and $f_{2}$;

- Generated heat source Q inside the component.

Keeping constant power dissipated inside the component, temperature distribution will depend on convective heat-transfer coefficient $(h)$ and ambient temperature $\left(T_{\mathrm{a}}\right)$.

Assuming constant power $Q=1 \mathrm{~W}$ dissipated inside the component in an environment of temperature $T_{\mathrm{a}}=30^{\circ} \mathrm{C}$, the effect of convective heat-transfer coefficient on temperature rise inside the integrated LC component will be studied.

For the convective heat-transfer coefficient $(h)$, four different physical situations [8] may be presented:

- $h \rightarrow \infty$, when outer temperature is fixed at the ambient value;

- $h=100 \mathrm{~W} / \mathrm{m}^{2} / \mathrm{K}$, representing forced convection;

- $h=10 \mathrm{~W} / \mathrm{m}^{2} / \mathrm{K}$, representing natural convection;

- $h=0$, representing adiabatic operation.

Temperature distribution for analytical calculation and FEM through the component for each physical situation of the heat-transfer coefficient is presented in Table 3.

Results of analytical calculation and FEM solution are shown in Figures $7(\mathrm{a})-(\mathrm{c})$.

Calculation and simulation for $h=0$ have not been reported, since temperature are unrealistically high for the multilayer integrated LC component.

The above table shows that the result obtained from analytical calculation and FEM simulation are very close. The agreement between the FEM solution and the analytical calculation is graphically demonstrated in Figure 7. Maximal temperature inside the multilayer integrated component depends on the type of convection on outer surface. Difference temperature between $T_{\max }$ and top outer face is small due to the weak thermal resistance of the ferrite layers. 
Table 3. Comparison between Analytical and FEM results of temperature distribution.

\begin{tabular}{|c|c|c|c|c|c|c|c|}
\hline \multirow{2}{*}{$\begin{array}{c}\text { Temperature } \\
{\left[{ }^{\circ} \mathrm{C}\right]}\end{array}$} & \multicolumn{2}{|c|}{$h \rightarrow \infty$} & \multicolumn{2}{|c|}{$h=100 \mathrm{~W} /\left(\mathrm{m}^{2} \mathrm{~K}\right)$} & \multicolumn{2}{|c|}{$H=10 \mathrm{~W} /\left(\mathrm{m}^{2} \mathrm{~K}\right)$} & \multirow{2}{*}{$\begin{array}{c}\text { Distance } \\
{[\mathrm{mm}]}\end{array}$} \\
\hline & Analytical & FEM & Analytical & FEM & Analytical & FEM & \\
\hline $\mathrm{T}_{\mathrm{f} 2}$ & 30.00 & 30.00 & 31.17 & 31.18 & 43.63 & 43.64 & 0 \\
\hline $\mathrm{T}_{3}$ & 30.00 & 30.00 & 31.19 & 31.20 & 43.65 & 43.66 & 0.2 \\
\hline $\mathrm{T}_{\max }$ & 30.10 & 30.11 & 31.66 & 31.67 & 44.19 & 44.20 & 1.82 \\
\hline $\mathrm{T}_{2}$ & 30.06 & 30.07 & 31.64 & 31.64 & 44.18 & 44.18 & 2.07 \\
\hline $\mathrm{T}_{1}$ & 30.03 & 30.03 & 31.62 & 31.61 & 44.16 & 44.15 & 2.30 \\
\hline $\mathrm{T}_{\mathrm{fl}}$ & 30.00 & 30.00 & 31.60 & 31.59 & 44.14 & 44.13 & 2.54 \\
\hline
\end{tabular}

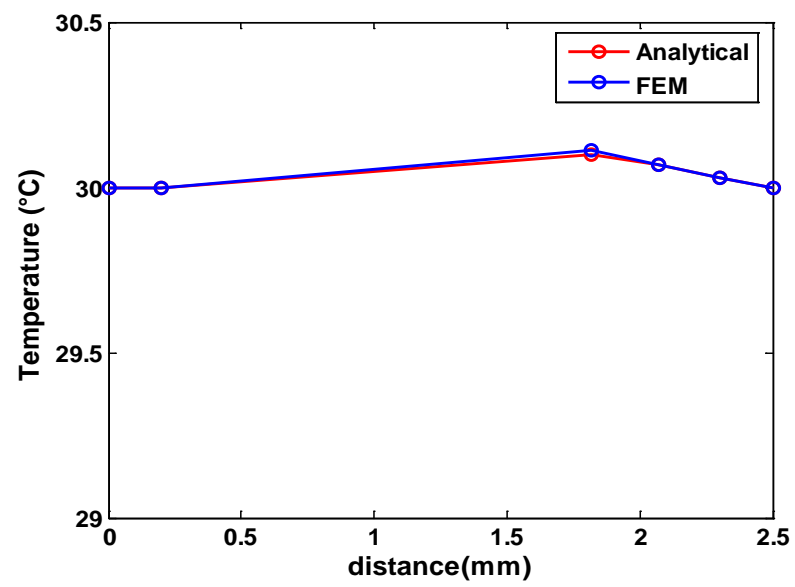

(a)

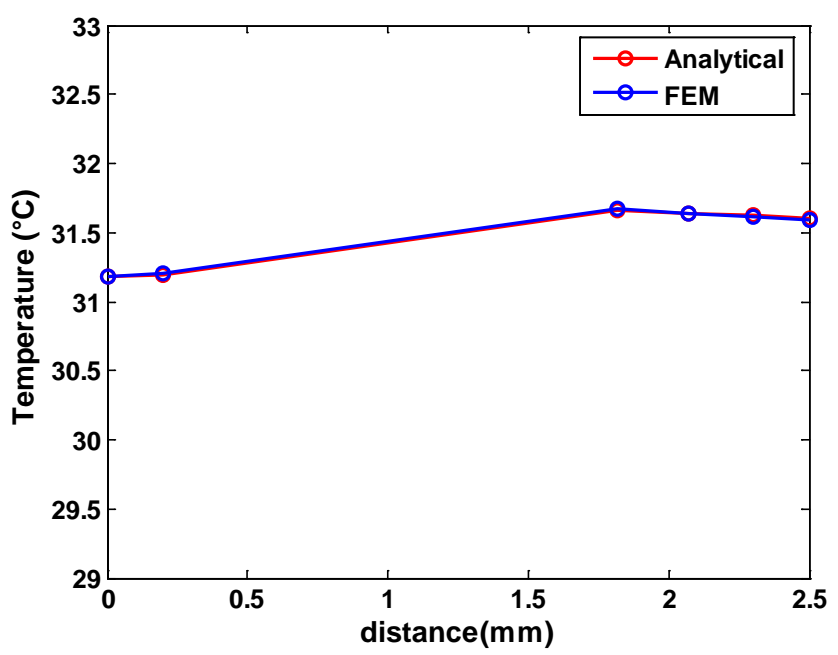

(b)

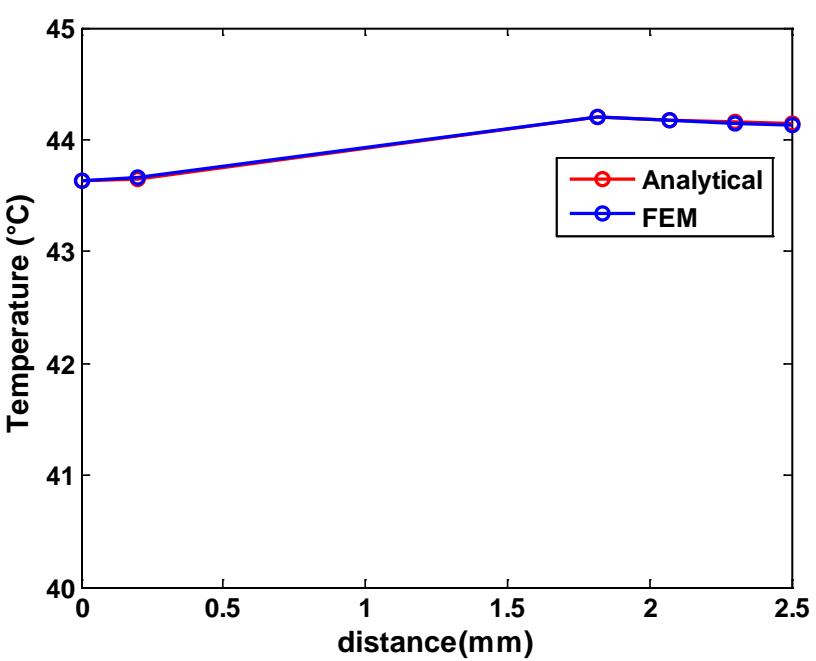

(c)

Figure 7. Comparison between analytical and FEM results of temperature distribution: (a) $h \rightarrow \infty$, (b) $h=100 \mathrm{~W} /\left(\mathrm{m}^{2} \mathrm{~K}\right)$, (c) $h=10$ $\mathrm{W} /\left(\mathrm{m}^{2} \mathrm{~K}\right)$.

From these results, it can be observed that for one-dimensional steady state heat conduction problem with uniform heat generation, thermal resistance approach can be used to investigate the temperature distribution inside the multilayer integrated LC component. 


\section{Conclusion}

In this paper, temperature distribution in a multilayer integrated LC has been carried out using conduction and convection heat transfer. Temperature distribution in the different material layers has been determined from thermal resistance approach knowing the generated heat source and multilayer material properties. Numerical validation of the results of the established model was done using heat transfer module of the FEMM software. A good correlation between analytical calculation using Matlab software and finite element method simulation tool for the temperature distribution in the integrated LC component has been observed according to the assumptions made.

\section{Acknowledgements}

The authors would like to thank Tanoh Aka for his useful discussions.

\section{Conflicts of Interest}

The authors declare no conflicts of interest regarding the publication of this paper.

\section{References}

[1] Hienonen, R., Karjalainen, M. and Lankinen, R. (1997) Verification of the Thermal Design of Electronic Equipment. Technical Research Centre of Finland (VTT).

[2] Coulibaly, S., Loum, G. and Diby, K.A. (2015) Design of Integrated LC Filter Using Multilayer Flexible Ferrite Sheets. IOSR Journal of Electrical and Electronics Engineerings (IOSR-JEEE), 10, 35-43.

[3] Coulibaly, S., Loum, G. and Diby, K.A. (2016) Implementation of an Integrated LC Component for the Output Filter of a Step-Down DC-DC Converter. American Scientific Research Journal for Engineering, Technology, and Sciences (ASJETS), 26, 178-189.

[4] Sippola, M. (2003) Developments for the High Frequency Power Transformer Design and Implementation. Dissertation for the Degree of Doctor of Science in Technology, Helsinki University of Technology, Espoo, Finland.

[5] Wolmarans, P.J. (2003) Investigation of a Class of Distributed Planar Conducted RF-EMI Filters for Integration in Power Electronic Converters. Dissertation of Magister Ingeneriae in Electrical and Electronic Engineering, Rand Afrikaans University, Johannesburg.

[6] Meeker, D. (2013) Finite Element Method of Magnetics. User's Manual, Version 4.2.

[7] Pusz, A. and Trojnacki, Z. (2012) The Modeling of Thermal Conductivity Measurements Using FEMM Application. Archives of Materials Science and Engineering, 53, 53-60.

[8] Gomadam, P.M., White, R.E. and Weidner, J.W. (2003) Modeling Heat Conduction in Spiral Geometries. Journal of the Electrochemical Society, A1339-A1345. https://doi.org/10.1149/1.1605743 